\title{
Historiografía Mapuche: balances y perspectivas de discusión en el Chile reciente. Conversación con Jorge Pinto Rodríguez
}

\author{
Mapuche historiography: balance and perspectives Index \\ in the recent Chile. Conversation with Jorge Pinto Rodríguez
}

Pedro Canales Tapia**

\begin{abstract}
Resumen
En el siguiente trabajo se presenta una mirada panorámica de la situación actual de lo que se ha dado a llamar Historiografía Mapuche. Por medio de la una conversación franca y necesaria con el historiador chileno y premio nacional e historia, Jorge Pinto Rodríguez, se va articulando una discusión que da cuenta de desafíos y proyecciones tanto para los investigadores y cientistas sociales Mapuche como en los procesos de dialogo con sus pares chilenos.
\end{abstract}

Palabras claves: Historiografía mapuche, intelectuales mapuche, Chile reciente, situación indígena, dialogo mapuche-chileno.

\begin{abstract}
In this paper a panoramic view of the current situation of what has been called Mapuche Historiography is presented. Through frank and necessary conversation with the Chilean historian and national and history prize, Jorge Pinto Rodriguez, it will articulating an argument that accounts for challenges and projections for both researchers and social scientists Mapuche as in the processes of dialogue with their Chilean counterparts.
\end{abstract}

Keyword: Mapuche Historiography, Mapuche intellectuals, recent Chile, indigenous status, Chilean Mapuche dialogue.

\section{Introducción}

Luego de la publicación del libro Escucha winka en 2006, la historiografía chilena ha ido tomando nota de los cuatros ensayos y el epilogo de futuro, como indica el sub titulo de dicho libro. Las propuestas Mapuche desde sitiales marcados por la letra y la investigación, desde los albores de la década de 1990 ya se vislumbraban en el horizonte. Desde 1989 el Centro de Estudios y Documentación Mapuche CEDM Liwen fue sistematizando un trabajo de discusión y análisis social y político desde la esfera Mapuche. José Marimán, por

\footnotetext{
* Este trabajo se inscribe dentro de las labores del proyecto FONDECYT №11121231, cuyo autor es investigador responsable.

** Chileno. Doctor. Académico e Investigador. Instituto de Estudios Avanzados. Universidad de Santiago de Chile. E mail: pedro.canales@usach.cl
} 
ejemplo, fue uno de los primeros interlocutores que se refirió a la autonomía como horizonte de lucha para el movimiento Mapuche de aquellos años ${ }^{1}$. Luego vinieron otras propuestas y enunciados, como los de "Mapuche urbano"2, "diáspora Mapuche" ${ }^{3}$ y reivindicación del trabajo de Manuel Manquilef en la primera parte del siglo $\mathrm{XX}^{4}$. Todos estos esfuerzos fueron abriendo el debate en Chile respecto de la historia y situación de los pueblos indígenas en este país, creciendo paulatina y sostenidamente la convicción de que Chile sigue siendo una estructura de poder marcadamente colonialista.

¿Cómo ha impactado este debate a las bases de las "formas de hacer historia” en Chile? ¿Se vislumbra en el horizonte un giro descolonizador en la pluma de nuestros historiadores e historiadoras? ¿O definitivamente, la letra y voz Mapuche siguen siendo -así como lo son las demandas de organizaciones y comunidades en Santiago y otras regiones de Chilemarginales?

Consignemos en este escenario, que el trabajo llevado a cabo por investigadores y cientistas sociales Mapuche, se ha dado en un contexto en el cual la historiografía y ciencias sociales chilenas, poseen su propia idea respecto de los Mapuche, su historia y presente. Desde la década de 1980, los estudios fronterizos liderados por Sergio Villalobos ${ }^{5}$ y los estudios interétnicos liderados por Rolf Foester, Sonia Montencino ${ }^{6}$ y José Bengoa ${ }^{7}$, fueron hilvanando un debate que de una u otra forma fue naturalizando la noción de mestizaje como punto clave en la discusión identitaria del país ${ }^{8}$. De esta forma, a pesar de que los detractores de Villalobos nieguen tal influjo, la tesis antiindígena de este historiador, se fue imponiendo. José Bengoa, por citar un caso, escribió Emergencia indígena ${ }^{9}$, refiriéndose a nuevos sujetos que en toda América Latina se fueron indianizando, en contextos de marcada mestización de la población. Este mismo autor, en más de una ocasión, defendió la máxima "desarrollo con identidad", idea que se identifica con la lógica multiculturalista de las políticas indigenistas propias del escenario globalizado.

En este contexto, la mirada del historiador Jorge Pinto Rodríguez, premio nacional de historia 2012, acerca de la cada vez mayor visibilización de historiografía Mapuche, resulta ser un ejercicio analítico, teórico y metodológico, necesario. En primer lugar, por el trabajo de décadas de este historiador en territorio Mapuche sobre la relación entre este pueblo y el estado chileno luego de 1883, hito materializado en el libro De la inclusión a la

\footnotetext{
${ }^{1}$ Mariman, José (1992). “Cuestión Mapuche, Descentralización del Estado y Autonomía Regional.” En Rehue Foundation. www.xs4all.nl/ rehue/art/jmar1.html

2 Ancan, José (1994). "Los urbanos: Un nuevo sector dentro de la sociedad mapuche contemporánea”, Pentukun 1. Temuco: Instituto de Estudios Indígenas, Universidad de la Frontera.

${ }^{3}$ Marimán, Pedro (1998). La Diáspora Mapuche: una Reflexión Política” En Liwen No 4. Temuco: Centro de Estudios y Documentación Mapuche Liwen. p. 216.

${ }^{4}$ Ancan, José (2002). Historias de familia. Temuco: CEDM Liwen.

${ }^{5}$ Villalobos, Sergio (1995). Vida fronteriza en la Araucanía. Santiago: editorial Andrés Bello.

${ }^{6}$ Foerster, Rolf y Montecino, Sonia (1988). Líderes, contiendas y luchas mapuche. Santiago: CEM.

${ }^{7}$ Bengoa, José (1985). Historia del pueblo mapuche. Santiago: Ediciones Sur.

${ }^{8}$ Ver Canales, Pedro (2010). Tierra e Historia. Estudios y controversias acerca de la historia Mapuche en Chile. 1950-2010. La Serena: Universidad de La Serena.

${ }^{9}$ Bengoa, José (1999). Emergencia indígena. Santiago: Fondo de Cultura Económica.
} 
exclusión $^{10}$; en segundo término, porque desde la docencia, este académico ha sido formador de varios de los historiadores Mapuche que hoy publicación y difunden sus trabajos, y en tercer lugar, porque Pinto propone claves para enfrentar el futuro y permanecer el tiempo como expresión investigativa de corte étnica.

Si bien en los años 80 Pinto fue parte importante de la línea denominada estudios fronterizos, con el paso de ellos, este investigador se fue distanciando de quien fuera su maestro y mentor, el ya mencionado Villalobos ${ }^{11}$.

En 1996 Pinto indica que el Estado luego de la ocupación militar de Wallmapu o Araucanía “(...) no logró la modernización en los niveles esperados; (...), no consiguió aplastar al mundo indígena $^{12}$. En 1998, por otro lado, agrega que el proindigenismo que él identifica entre algunos actores en la segunda mitad de la centuria decimonónica, no se pudo imponer frente al macizo antiindigenismo chileno que irrumpió en territorios mapuche en "aras" del “progreso" y la "civilización” 13 . Juicio que ratifica y fundamenta en el texto de la Inclusión a la exclusión, el cual reivindica el valor de la historia regional y la urgencia de asumir la situación Mapuche en la Araucanía, como un tema país, que no debe ser reducido a medidas economicistas, sino a formulas políticas que "paguen la deuda” que el estado chileno detenta con los Mapuche. En septiembre de 2012, Pinto declara en el Diario Austral de Temuco: "El estado no logró construir una identidad regional, que es lo más delicado" ${ }^{14}$. Cuestión que pasa inexpugnablemte por el no reconocimiento de los Mapuche como habitantes y legítimos propietarios de los territorios ocupados y entregados a colonos.

De este modo, la elaboración de este trabajo, conjuga la rigurosidad de una propuesta investigativa, con la subjetividad de opiniones y pareceres en torno a la coyuntura social política Mapuche hoy en Chile, más la evaluación a la tarea de historiar de sujetos que desde su acerbo indígena, su experiencia como colonizados entre colonizados como indican los autores de Escucha winka, hacen del debate de las ciencias sociales un reducto que ha ido ampliando sus fronteras, sus énfasis y nodos discursivos. Teóricamente podríamos consignar, las respuestas e interpelaciones de Jorge Pinto a la historiografía Mapuche de hoy en Chile, son parte del ejercicio interpretativo que en la década de 1980 Guillermo Bonfil Batalla presentó como teórica del control cultural en contextos étnicos. La asimilación y los elementos externos o no mapuche, han ido configurando una figura reivindicativa desde la historia, que fundamenta en el tiempo el proyecto autonómico que el movimiento mapuche ha ido erigiendo durante décadas.

\section{Emergencia y visibilización de las “letras” Mapuche}

\footnotetext{
${ }^{10}$ Pinto, Jorge (2001). Formación del estado y pueblo mapuche. De la Inclusión a la exclusión. Santiago: IDEA-USACH.

${ }^{11}$ Canales, Pedro (2010). Tierra e Historia...Op. Cit.

12 Pinto, Jorge (1996). "Del antiindigenismo al proindigenismo en Chile en el siglo XIX”, en Jorge Pinto (edit) Del discurso colonial al proindigenismo. Temuco: Ediciones Universidad de La Frontera. p. 107.

13 Pinto, Jorge (1998). “Araucanía, 1750-1850. Un mundo fronterizo en Chile a fines de la Colonia y comienzos de la República”, en Jorge Pinto (edit) Modernización, inmigración y mundo indígena. Temuco: Ediciones Universidad de La Frontera. p. 111.

${ }^{14}$ Diario Austral. Temuco. 2012: 8.
} 
Luego de Escucha winka, nuevos textos Mapuche han ido destacando y aportando en la apertura del debate y el trabajo disciplinario. José Marimán en 2012 publicó Autonomía. Ese mismo año Héctor Nahuelpan y otros historiadores Mapuche editaron Ta iñ fijke xipa rakizuameluwün. Historia, colonialismo y resistencia desde el país Mapuche; también se presentó un dossier de historia Mapuche en la revista de historia social y de las mentalidades de la USACH ${ }^{15}$. El año 2014 destacaron los libros de jóvenes historiadores como José Luis Cabrera Llancaqueo y su trabajo Machi Mongen tani Santiago Warria New ${ }^{16}$ y más recientemente Fernando Pairican presentó Malón. La rebelión del movimiento mapuche ${ }^{17}$.

En este sentido, Profesor Pinto ¿Qué opinión tiene usted sobre estas producciones historiográficas?

A mí me parece que son aportes muy interesantes, porque son producto de una mirada distinta a la que tenemos los historiadores no mapuche, por lo tanto yo valoro el esfuerzo que están haciendo los jóvenes historiadores mapuche, porque me da la impresión que están contribuyendo notablemente al conocimiento que debemos tener de lo que ocurrió aquí en la región de La Araucanía. Creo que aportan no solo nuevas miradas, sino que refrescan la historiografía, la ventilan y de alguna manera aportan un conocimiento que nosotros no podemos producir.

¿Usted le haría alguna crítica a esta mirada propia de la historia que tienen estos investigadores?

$\mathrm{Si}$, yo me atrevería a formular un par de observaciones. Primero, en algunos autores, no en todos -no los voy a identificar en particular-, pero en algunos de ellos veo una dosis de resentimiento que es muy explicable, pero que a lo mejor sería conveniente contener, en la medida en que se está tratando de construir un conocimiento, que debería... no sé cómo decirlo precisamente, pero contener o bloquear esos factores que podrían quizás afectar un poco la mirada que se le quiere dar a los acontecimientos del pasado. Bueno, ellos mismos lo dicen en el "Escucha wingka”, "Muchos nos dirán resentidos y tal vez lo somos”, dicen ellos textualmente. Yo creo que eso podría generar una suerte de barrera.

Los invitaría a reflexionar sobre eso. Eso en primero lugar. En segundo lugar, por lo mismo, yo creo que ellos también deberían hacer un esfuerzo por valorar lo que hacen algunos historiadores wingkas, en un esfuerzo por comprender mejor y desde una óptica distinta lo que se ha venido sosteniendo respecto de lo que ocurrió aquí en La Araucanía, de

\footnotetext{
${ }^{15}$ Ver Nahulpan, Héctor et al (2012). Ta iñ fijke xipa rakizuameluwün. Historia, colonialismo y resistencia desde el país Mapuche. Santiago: Comunidad de historia mapuche; Ver revista de historia social y de las mentalidades. $\mathrm{N}^{\circ} 16$. 2013. USACH.

${ }^{16}$ Cabrera Llancaqueo, José (2014). Machi Mongen tani Santiago Warria New. Santiago: Grupo de trabajo Kuifike.

${ }^{17}$ Pairican, Fernando (2014). Malón. La rebelión del movimiento mapuche, 1990-2010. Santiago: Pehuén editores.
} 
tal modo que yo, tal vez, recomendaría una cierta dosis de equilibrio en ese sentido, pero eso, naturalmente, no impide valorar lo que ellos están haciendo.

\section{Viabilidad y permanencia historiográfica Mapuche}

En 1989 nación el CEDM Liwen en Temuco. Su aporte a los estudios Mapuche fue innegable; por dicha institución pasaron importantes representantes Mapuche como Margarita Calfío, José Mariman, José Ancán y Pablo Mariman entre otros. En 2005 Liwen cerró sus puertas ${ }^{18}$. Hacía 2012 gracias a un esfuerzo colectivo surge la Comunidad de Historia Mapuche, la cual se organiza desde la autogestión e independencia de su proyecto respecto de la institucionalidad chilena, como una forma de viabilizar su proyección en el tiempo y constituir en un efectivo referente discursivo y político frente a la alteridad colonial.

Con respecto a este movimiento historiográfico ¿Usted cree que va a permanecer en el tiempo?, ¿O a la larga está destinado a desaparecer, como le sucedió luego de dieciséis años el CEDM Liwen, por ejemplo?

Pero Liwen hizo un aporte muy importante; creo que Liwen hoy día no tiene la prestancia que tuvo hace algunos años, pero sentó un piso a partir del cual muchos de estos jóvenes historiadores mapuche han empezado a operar, por lo tanto yo no desmerecería el aporte que hizo Liwen. Allí se forjaron los primeros historiadores de esta nueva generación de historiadores, entre ellos los hermanos Mariman, bueno, quien se alejó de la historia hoy día Alfonso Cayul y varios jóvenes que en los años 80-90 básicamente, a fines de los 90 yo creo, en la década de los 90, dieron forma a este movimiento que se asocio a Liwen.

Que va a pasar en el futuro? Uno no tiene la bola de cristal para saber que va a pasar, pero yo creo que en la medida en que estos historiadores que han adquirido un cierto grado de madurez cómo Héctor Nahuelpan, Sergio Caniuqueo o Pedro Mariman, bueno a la cabeza de ellos José Mariman, Pablo Mariman, en la medida en que ellos se propongan formar nuevas generaciones de historiadores mapuche, incorporando aún a jóvenes historiadores no mapuche, creo que se van a proyectar en el tiempo. Por lo tanto yo tengo la confianza y la esperanza, la esperanza más bien, de que ellos van a ser capaces de proyectarse en el tiempo.

Respecto a lo que usted señalaba hace un momento. Los trabajos de historiadores Mapuche han sido "virulentos contra algunos trabajos de profesores $e$ investigadores wingka o no mapuche, ¿Cómo evalúa esta actitud?

Yo los invitaría a reflexionar sobre lo mismo, porque no se puede desconocer el aporte que ha hecho José Bengoa por ejemplo. La verdad es que estos jóvenes historiadores están muy

\footnotetext{
18 Marimán, Pablo (2011). "Pensar y hacer como Mapuche”. Lasa Forum. Volumen XLIII. Chicago: Latin American Studies Association. 2013. pp. 14-16.
} 
marcados por quienes han sido sus maestros en la universidad, no mapuches y yo creo que las disputas que hay entre los historiadores no mapuche sobre los temas que tienen que ver con lo que ocurrió aquí en La Araucanía, la disputa entre esos profesores, de algún modo se expresa en los juicios de estos historiadores, que paradojalmente hoy día se sienten muy cercanos a historiadores, cuya producción historiográfica en este último tiempo, yo creo que a lo menos es discutible, a lo menos es discutible. Pero fueron estos profesores, cuya producción hoy día es discutible, los que los han marcado sobre todo en la Universidad de Chile.

Entonces yo los invitaría a reflexionar, porque no se puede desconocer el aporte que hizo José Bengoa, es imposible. Ellos hablan de un amiguismo también, en general yo creo que esas actitudes poco contribuyen a generar una cierta solidaridad en el proceso de construcción de conocimiento, sea mapuche o no mapuche. Yo sobre eso los invitaría a reflexionar.

Existen interlocutores chilenos que clasifican como racista la actitud de algunos investigadores Mapuche, por ejemplo cuando fundan la Comunidad de Historia Mapuche sólo con miembros Mapuche ¿Es contraproducente aquello?

¡No!, no lo considero racista porque es el mismo derecho que tenemos los historiadores latinoamericanos a plantear una historia latinoamericana. Los historiadores chilenos a la hora de plantear una historiografía chilena, los historiadores argentinos... Yo creo que eso corresponde a un sentimiento de identidad que se expresa en cualquier parte del mundo, por lo tanto yo no lo consideraría una postura racista. Ahora, por otra parte, en este último tiempo ellos se están abriendo a jóvenes historiadores no mapuche que están participando, colaborando. Tu mismo no eres un historiador mapuche, por lo tanto yo no diría que no... se observa una apertura en estos jóvenes historiadores, que están incorporando a jóvenes historiadores.

Creo que más bien es un tema generacional de jóvenes mapuche que se encuentran con su historia aquí en la Universidad de La Frontera, porque la mayoría se formó aquí en la Universidad de La Frontera, por no decir casi todos. Bueno, hay algunos que no se han formado en la Universidad de La Frontera y que no tengo tan claro que estén incorporados a este grupo de historiadores mapuche; el Fernando Pairican por ejemplo, entre otros. No sé si estará incorporado, yo en realidad no he conversado últimamente con Fernando, pero me da la impresión de que no están incorporados.

También el antropólogo Enrique Antileo, entre otros...

Exactamente, hay varios más... Cesar Loncón que estuvo haciendo algunos aportes interesantes tiempo atrás. No sé si estarán incorporados, pero yo no los considero racistas.

Me parece muy legítimo que ellos generen una producción historiográfica en su condición de historiadores mapuche. Y en segundo lugar, porque creo que en este último tiempo ha habido una apertura de parte de ellos. Yo valoro mucho el trabajo de Sergio Caniuqueo, 
creo que de estos jóvenes historiadores al que veo con más porvenir es a Sergio Caniuqueo. Un historiador mapuche que ha madurado, un historiador mapuche que está participando de una serie de proyectos, un historiador mapuche que ha trascendido a La Frontera. Héctor Nahuelpan ha hecho aportes muy interesantes y, por cierto, los más maduros como los hermanos Mariman y otros jóvenes historiadores que hoy día están en el extranjero.

\section{A propósito de enfoques y disputas}

Los historiadores y cientistas sociales chilenos que han estudiado en los últimos años la historia Mapuche han ido poniendo el acento en aspectos que vinculan directamente a los Mapuche con las diferentes aristas de la historia chilena, occidental, capitalista y republicana. En este sentido, la centralidad de la lógica y sabiduría Mapuche, siempre fueron quedando relegadas a un segundo plano, lo cual establece un control de corte colonial, que tiende a poner cerrojo a las expresiones históricas Mapuche. En parte, es lo que Héctor Nahuelpan denomina las “zonas grises” de la historia Mapuche ${ }^{19}$.

Respecto a este diagnóstico colonialista que hacen autores Mapuche ¿Qué comentarios tiene usted de este diagnóstico contra la historiografía chilena?

Tengo la impresión de que ellos tienen el legítimo derecho a calificar la historiografía no mapuche del modo que la califica. Es un derecho muy legítimo, por lo tanto yo no cuestionaría aquellas observaciones, porque son producto de una vieja historia colonialista que ya no tiene que ver con los historiadores no mapuche, sino que tiene que ver con lo que hizo la Corona y con lo que hizo el Estado. Por lo tanto, en tanto a nosotros nos ven como historiadores miembros del Estado chileno, es obvio que tengan la tentación de considerarnos historiadores colonialistas.

Creo que no está la intención en nosotros de ser historiadores colonialistas, pero como este tema no lo hemos discutido con ellos, yo no recuerdo algún foro en donde yo haya estado presente, en que se haya discutido esto, me quedo con la idea de que tienen legítimo derecho a hacer las observaciones que ellos están haciendo, cómo yo también tengo derecho a hacer algunos cuestionamientos a la labor que ellos hacen. Eso está dentro de las reglas del juego y el respeto es lo que se impone en este caso.

Profesor, con respecto a Sergio Caniuqueo, Héctor Nahuelpan, Pablo Mariman y otros historiadores Mapuche que en estos momentos están en un fuerte proceso de producción intelectual, ¿Cuál es su evaluación respecto del trabajo intelectual de ellos?

A ellos no les gusta que los llamemos intelectuales mapuche.

Exactamente, no les agrada y tiene sus razones.

\footnotetext{
${ }^{19}$ Ver Nahuelpán, Héctor (2013). “Las “zonas grises” de las historias Mapuche”. Revista de Historia Social y las Mentalidades. $\mathrm{N}^{\circ} 17$. Santiago: USACH.
} 
Pero es que no tengo otro término en realidad. Podríamos hablar de historiadores mapuche. Yo hablaría de historiadores mapuche, tratándose de esta gente que se ha formado en el campo de la historia. No sé como denominar a Pedro Cayuqueo que es un periodista, pero que a la vez es un intelectual mapuche, a Fernando Pairican que desborda muchas veces la historia, para analizar temas contingentes. El propio José Mariman. José Mariman, yo creo que ha desbordado la historia, se ha incorporado hoy día o ha incorporado su acervo a la ciencia política. Para mi José Mariman por ejemplo, es básicamente un intelectual mapuche $^{20}$. Un intelectual mapuche que con los años se va a convertir en un sabio, como los viejos sabios mapuche.

¿Qué les podría decir a estas nuevas generaciones Mapuche que se están formando en la Universidad de La Frontera y otras Universidades, que están incursionando en estos estudios y se han ido organizando en colectivos como el grupo de descolonización Leeliaiñ Taiñ Aiwiñ, que funcionó hace un tiempo, en donde destacaban Sergio Caniuqueo, Jaime Antimil, Juan Porma y chilenos como Patricio Macaya.

Que perseveren, que no se desanimen por las dificultades que tienen, yo entiendo, en el ámbito laboral. Estos jóvenes no tienen el suficiente apoyo, solo uno y otro hoy está instalado en el sistema universitario. Recuerda el caso de Héctor Nahuelpan, que está con una beca pos doctoral acá en la Universidad de La Frontera que tiene medianamente resuelta con el tiempo su situación económica, pero conozco de los sacrificios que tiene que hacer Sergio Caniuqueo, que tiene que hacer Pablo Mariman.

No se desalienten, que perseveren, que sigan. Que lo están haciendo bien y que el país necesita una generación de historiadores mapuche, sobre todo una generación de historiadores jóvenes y que tendrán siempre aquí, en nosotros, los historiadores de la Universidad de La Frontera, el apoyo que ellos requieran, de manera que mis palabras son de estímulo y de confianza en que van a ser capaces de salir adelante con su proyecto y sobre todo en este país, que no se ha caracterizado por una mirada muy amplia. A abrir la consciencia a un tema que muchos chilenos que nosotros hemos olvidado, hemos invisibilizado.

\section{De la historia a la política: figuras y movimientos}

\footnotetext{
20 Canales, Pedro (2012). “Intelectualidad mapuche, problemáticas y desafíos. Conversación con el historiador José Marimán Quemenado”. Revista Cuicuilco, Núm 63, México: Escuela Nacional de Antropología e Historia. p. 223.
} 
El escenario actual en Chile, a la hora de discutir de la situación social, política y/o cultural Mapuche, necesariamente se relaciona con figuras destacadas como el Intendente de la Araucanía, Francisco Huenchumilla o el actual embajador en Guatemala, Domingo Namuncura. En caso Huenchumilla ha sido parte del proceso Mapuche por instalar sus voces, demandas y propuestas en mesas de discusión nacionales. Dicho intendente ha dado declaraciones impensadas en otras épocas: ha sindicado al estado como responsable de la situación de violencia vivida en la región; ha pedido perdón a nombre del Estado a los Mapuche por la violencia y abusos en su contra y ha dicho que se quemaría a lo bonzo para asegurar la "paz social” en su región ${ }^{21}$.

Salgamos un instante del debate central de esta conversación. A propósito de la coyuntura nacional y la figura del Intendente Huenchumilla y todo el revuelo que ha causado su actuar político ¿Cree que en Chile y en la región de la Araucanía se está produciendo algún tipo de proceso de descolonización?, ¿Cuál, cree usted, que es el propósito político de Intendente y su actuar?

La actitud de Huenchumilla no es nueva, de ninguna manera. Yo hace ya 14 años publiqué por primera vez el libro "La formación del Estado, la nación y el Pueblo Mapuche”, y en ese libro yo incorporo expresiones de Francisco Huenchumilla. Yo estoy hablando de fines de los años 90.Y en esta oportunidad Huenchumilla hacía algunos planteamientos que yo recogí cuando Huenchumilla, si mal no recuerdo era Parlamentario o era Ministro Secretario General de Gobierno y Huenchumilla aparece aquí en el texto, en la contratapa [Jorge Pinto procede a mostrar un ejemplar de la primera edición del texto mencionado], yo digo lo siguiente, cito a Aukan Huilcaman sin nombrarlo, vientos de guerra en La Araucanía estoy diciendo yo y Aukan señalaba que la nacionalidad chilena es una idea que no tiene más de 200 años, mientras que la mapuche tiene miles de años.

Y aquí cito entre comillas, “(...) la sociedad de hoy agregaba un diputado de la zona -en ese tiempo era diputado Huenchumilla- está pagando los pecados cometidos hace 120 años en la mal llamada Pacificación de La Araucanía. El Ministerio del Interior y la Intendencia cometen un grave error -o comenten un error, para ser más preciso- al pensar que el problema mapuche se reprime como se hace con las protestas en Santiago. De esa forma solo se toca la superficie y no se va al fondo del asunto (...)" Esta es una cita textual del actual Intendente Huenchumilla, y esto lo planteo Huenchumilla en los años 90, por lo tanto, quienes han seguido la trayectoria de Huenchumilla no tendrían por qué sorprenderse de lo que está planteando hoy día.

Estuve con Francisco Huenchumilla el año pasado en ENAMA, en ese momento, en la reunión de ENAMA, Huenchumilla, no era Intendente todavía; planteó que el tema de las forestales tenía que enfrentarse ahí. Es más, el planteo allí de sacar a las forestales de la

\footnotetext{
${ }^{21}$ El Diario Austral de Temuco desde marzo de 2014 ha seguido en detalle la seguidilla de declaraciones del Intendente. Organizaciones de agricultores y colonos han pedido en más de una ocasión la renuncia de la autoridad, acusándolo de parcial frente a lo que se ha dado a llamar el "conflicto Mapuche”.
} 
región. Entonces Huenchumilla ha tenido una trayectoria muy coherente y en este sentido a mi no me han sorprendido sus declaraciones como Intendente de la región y yo las comparto plenamente.

El intendente ha dicho que está dispuesto a hacer todo lo posible por instalar la paz acá en la región, porque tenemos que resolver este conflicto que de otra manera está hipotecado el futuro de la Araucanía, de tal manera que yo no solo comparto los dicho de Huenchumilla, sino que quiero destacar que lo que viene planteando hoy día como intendente es lo que ha venido sosteniendo Huenchumilla desde hace muchos años. Huenchumilla fue invitado a presentar este libro, lo presentó aquí en Temuco y yo, precisamente, lo invité a presentarlo, porque yo había recogido de la prensa estas citas del entonces diputado Francisco Huenchumilla $^{22}$.

¿Cuál será el futuro del actuar político de Huenchumilla?, ¿En qué va a terminar la tensión entre este Intendente Mapuche y las fuerzas que rechazan su estilo y decisiones?

Eso dependerá de la manera de cómo se comporte la fuerza política del país. Yo creo que es incierto saber lo que va a pasar, a lo menos a colocado el tema en la agenda pública. Ha generado una mayor sensibilidad. Yo voy a estar probablemente en un foro con Francisco Huenchumilla y el Senador Espina, e próximo mes. En septiembre creo que está convocado un foro y ahí voy a poder conocer más a fondo lo que está planteando Huenchumilla en términos de una estrategia política.

Lo que yo veo en Huenchumilla hoy día es una coherencia con lo que él ha venido planteando, pero no se hacia donde apunta en términos concretos, porque yo no estoy interviniendo en el mundo político y no sé cuales con las alianzas, cuales son los puntos de apoyo de Huenchumilla, al margen de las declaraciones de buena crianza que hace el Ministro del Interior y la presidencia de la República en el sentido de apoyarlo.

Profesor, y acá en el debate, ¿Cuál es la influencia que puede tener la Universidad de La Frontera como universidad regional a este debate?

Lamentablemente es muy poca. Yo creo que la Universidad de La Frontera se ha desentendido de este tema. Yo creo que hay razones que tienen que ver con lo que es la Universidad de La Frontera como universidad estatal, comprometida con todos los sectores de la sociedad regional. Yo creo que en ese sentido, quizá una de las críticas que yo le podría hacer a la Universidad de La Frontera, es haber tenido, como institución, quizás, la palabra es fuerte, pero quizás falta de valentía para enfrentar esta situación. Denunciando los abusos, pero al mismo tiempo proponiendo soluciones, pensando que este es un tema que afecta tanto a las comunidades mapuche como a los agricultores de la región. O sea la

\footnotetext{
${ }^{22}$ El libro al que Jorge Pinto se refiere es a La Formación del Estado y el Pueblo Mapuche. De la inclusión a la exclusión. Editado en 2001 por el Instituto de Estudios Avanzados de la USACH.
} 
Universidad de La Frontera podría ser un agente mediador hoy día quizás, por el peso que tiene una universidad estatal en una región como esta. Pero lamentablemente yo creo que los vientos que soplan en la Universidad de La Frontera se han alejado un poco de este conflicto, con el cual -parece- las autoridades no quieren comprometerse, involucrarse.

Lo último ¿Cómo visualiza la lucha del movimiento indígena en Chile respecto de experiencias como la boliviana y ecuatoriana?

Yo creo que en los últimos 20 años se ha ido produciendo simultáneamente en América Latina movimientos indígenas que han brotado en México, en Guatemala, en Ecuador, en Perú, en Bolivia, en Argentina y en Chile por cierto. En algunas partes con más fuerza y en otras con menos fuerza, pero es que yo diría que a partir de los años 90 América Latina cambia y empiezan a levantar su voz estos grupos que habían sido invisibilizados, sometidos, aplastados muchas veces. Yo diría que estos movimientos tienen su propia energía.

Están asociados a fuerzas muy profundas que han recorrido una larga historia, pero también están marcados por las coyunturas que vivimos en América Latina. Nunca olvida las palabras de Domingo Namuncura, que entiendo que hoy día está de embajador allá en Guatemala. Namuncura cuando escribió el libro sobre Ralco, tiene que haber sido a mediados de los 90, Namuncura recordó una reunión que se hizo en Atacama, San Pedro de Atacama, una reunión que convocó a los pueblos originarios de todo Chile y en ese momento el dijo “(...) nosotros venimos desde largas distancias a juntarnos acá en San Pedro de Atacama, pero no solo venimos desde largas distancias, sino que también venimos de una larga historia de represión, de invisibilización, de olvido, de postergación (...)” Y ese largo recorrido de discriminación, de represión, se ha ido instalando en la memoria colectiva.

Creo que ese es el punto de partida de estos movimientos que surgen en Chile, en Ecuador y en varios otros países. Pero también matizados por las coyunturas de la época. Así es que confianza a estos jóvenes historiadores mapuche. Que perseveren.

\section{Conclusiones}

Luego de 2006 los estudios Mapuche fueron incluyendo de manera permanente la discusión en torno al colonialismo chileno y las formas que este ha ido asumiendo a lo largo de los años. Jorge Pinto en la Universidad de La Frontera fue protagonista activo de la erección de este diagnóstico. En otras zonas de América Latina, los estudios post coloniales y otros denominados decoloniales, hay detenido su preocupación en los aspectos adaptativos, culturalmente, de los pueblos indígenas de la región. Salvo contadas excepciones, no escudriñan mayormente en las propuestas políticas de transformación y cambio y menos dialogan para lograr, con referentes indígenas ${ }^{23}$. ${ }^{23}$ En los últimos años en Chile han proliferado los libros que se detienen el esta discusión. Algunos ejemplos:
NAHUELPAN, Héctor et al (2012). Tai ñ fijke xipa rakizuameluwün, historias, colonialismo y resistencia 
Ahora bien, son muchas las interrogantes que desnudan las palabras de Pinto a la hora de referirse a los investigadores y cientistas sociales Mapuche que han ido poniendo en la palestra, aspectos que en discusiones pretéritas no se vislumbraban. El autor, por ejemplo, hace mención al tono del lenguaje de algunos interlocutores Mapuche, especialmente cuando critica el tenor de referencias a trabajos de historiadores chilenos como Bengoa, indica él.

Las preguntas entonces se multiplican y focalizan la atención de la discusión. ¿Estamos frente a una nueva semántica histórica? ¿Son los estudios Mapuche ejercicios que más que descomprimir han afectado los vasos comunicantes entre especialistas? ¿Es el colonialismo y su peso justificativos que den pie a la no - comunicación con otros, con investigadores no indígenas? ¿O es de esperar que el diagnostico de descolonización que se ha ido articulando pueda ser un eje transversal en la historiografía, universidades y foros que existen en este país?

Frente a este panorama, podemos articular al menos tres indicaciones para la reflexión y el análisis.

La primera de ellas tiene que ver con la preocupación de Jorge Pinto respecto del aporte de los estudios históricos Mapuche acerca de su pueblo, en escenarios urbanos y rurales. Al respecto, este premio nacional, es tajante en apoyar las nuevas miradas, más aún cuando varios de estos estudiosos fueron sus estudiantes en aulas universitarias en Temuco; no obstante, este respaldo no se engarza a una propuesta política de fondo en este autor. Lo que Pinto plantea es valioso pero "no se sale" de lo que ya ha dicho anteriormente, específicamente cuando hace suyo el peso de la historia regional y reconoce que la Araucanía es un espacio excepcional sobre el cual se deben tomar medidas excepcionales para lograr, en palabras del intendente Francisco Huenchumilla, la “paz social”.

Este punto, nos lleva a una segunda consideración. Si bien este autor, no rechaza el diagnóstico que apunta al colonialismo chileno como gran motor de la situación de discriminación, violencia y pauperización Mapuche, tampoco se suma a este debate. En términos teóricos, la postura de este autor es eminentemente una opinión personal en base a la experiencia propia y el vínculo con ex alumnos Mapuche. Su mirada política centra su mirada en relaciones de poder entre Mapuche y chilenos, mediadas por el Estado. En este ápice, el autor reconoce el aporte a la historia de varios referentes Mapuche como José Mariman, Pablo Mariman, Sergio Caniuqueo, Héctor Nahuelpan, y uno que no fue su alumno, Fernando Pairican. En este núcleo, Pinto referencia su anhelo de comunicación permanente y trabajo historiográfico riguroso.

desde el país Mapuche. Temuco: Edición Comunidad de Historia Mapuche; PAIRICAN, Fernando (2014). Revista de historia social y de las mentalidades. No 17. Santiago: USACH; OLIVA, Elena, STECHER, Lucía y ZAPATA, Claudia (2013). Frantz Fanon desde América Latina. Lecturas contemporáneas de un pensador del siglo XX. Buenos Aires: Corregidor y CNALES, Pedro y REA, Carmen (2013). Claro de luz. Descolonización e “intelectualidades indígenas” en Abya Yala. Chile: IDEA-USACH. 
Por último, en tercer término, las palabras de Jorge Pinto dan pie a proyectar como corriente historiográfica, el impulso Mapuche por escribir desde sus propios sitios, la historia de los suyos; considerando el kimün o conocimiento Mapuche, sus instituciones comunitarias, los aspectos pedagógicos de estos y las nuevas realidades en la ciudad warria, espacios en los que a diario se resignifica la existencia y los códigos de vida.

El sueño de Pinto pasa por la reparación del Estado chileno a los Mapuche. Se refiere a nuevas expresiones de comunicación y entendimiento; esto quedó más que claro en la entrevista que Pedro Cayuqueo le hizo a este profesor en el capítulo cinco del programa Kulmapu, cuando Pinto indica que a principios del siglo XIX hubo una gran admiración hacia los Mapuche, como necesidad de crear un discurso épico de fundación del país. Para este autor, esta referencia decimonónica es clave pues hace referencia a una readecuación que transforma la identidad en sujeto de estudio y da pie a la construcción de nuevos imaginarios; lo que pinto denomina "cruzar puentes”, concluyendo que “(...) la historia marcada por la tristeza, el abusos, la violación es la que tenemos que tratar de superar” 24 .

\section{Bibliografía}

ANCAN, José (1994). "Los urbanos: Un nuevo sector dentro de la sociedad mapuche contemporánea”, Pentukun 1. Temuco: Instituto de Estudios Indígenas, Universidad de la Frontera.

ANCAN, José (2002). Historias de familia. Temuco: CEDM Liwen.

BENGOA, José (1985). Historia del pueblo Mapuche. Santiago: Ediciones Sur.

BENGOA, José (1999). Emergencia indígena. Santiago: Fondo de Cultura Económica.

CABRERA LLANCAQUEO, José (2014). Machi mongen tani Santiago warria mew. Santiago: Grupo de Trabajo Kuifike.

CANALES, Pedro (2010). Tierra e historia. Estudios y controversias acerca del pueblo Mapuche en Chile, 1950-2010. La Serena: Editorial Universidad de La Serena.

CANALES, Pedro (2012). “Intelectualidad mapuche, problemáticas y desafíos. Conversación con el historiador José Marimán Quemenado”. Revista Cuicuilco, Núm 63, México: Escuela Nacional de Antropología e Historia. 223-235.

\footnotetext{
${ }^{24}$ Ver http://www.cnnchile.com/programa/kulmapu/capitulo/2431
} 
CANALES, Pedro y REA, Carmen (2013). Claro de luz. Descolonización e “intelectualidades indígenas" en Abya Yala. Chile: IDEA-USACH.

CAYUQUEO, Pedro (2014). Kulmapu. Capítulo 5. En: http://www.cnnchile.com/programa/kulmapu/capitulo/2431

DIARIO Austral (2012). Temuco. Chile.

FOERSTER, Rolf y MONTECINO, Sonia (1988). Líderes, contiendas y luchas mapuche. Santiago: CEM.

MARIMAN, José (1992). “Cuestión Mapuche, Descentralización del Estado y Autonomía Regional.” En Rehue Foundation. www.xs4all.nl/ rehue/art/jmar1.html

MARIMAN, José (2012). Autodeterminación. Santiago: ediciones Lom.

MARIMAN, Pedro (1998). "La Diáspora Mapuche: una Reflexión Política” En Liwen No 4. Temuco: Centro de Estudios y Documentación Mapuche Liwen. 216-223.

MARIMAN, Pablo et al (2006). !!!...Escucha, winka....iii Cuatro Ensayos de Historia Nacional Mapuche y un Epílogo Sobre el Futuro. Santiago: Editorial Lom.

MARIMAN, Pablo (2011). "Pensar y hacer como Mapuche”. Lasa Forum. Volumen XLIII. Chicago: Latin American Studies Association. 2013. 14-16.

NAHUELPAN, Héctor et al (2012). Tai $\tilde{\mathbf{n}}$ fijke xipa rakizuameluwün, historias, colonialismo y resistencia desde el país Mapuche. Santiago: Edición Comunidad de Historia Mapuche.

NAHUELPAN, Héctor. "Las "zonas grises" de las historias Mapuche". Revista de Historia Social y las Mentalidades. $N^{\circ}$ 17. Santiago: USACH. 2013. 9-31.

OLIVA, Elena, STECHER, Lucía y ZAPATA, Claudia (2013). Frantz Fanon desde América Latina. Lecturas contemporáneas de un pensador del siglo XX. Buenos Aires: Corregidor.

PAIRICAN, Fernando (2014). Revista de historia social y de las mentalidades. N ${ }^{\circ} 17$. Santiago: USACH.

PAIRICAN, Fernando (2014). Malón. La Rebelión del movimiento mapuche. 19902010. Santiago: Pehuén editores.

PINTO, Jorge (1996). "Del antiindigenismo al proindigenismo en Chile en el siglo XIX", en Jorge Pinto (edit) Del discurso colonial al proindigenismo. Temuco: Ediciones Universidad de La Frontera. 
PINTO, Jorge (1998). “Araucanía, 1750-1850. Un mundo fronterizo en Chile a fines de la Colonia y comienzos de la República”, en Jorge Pinto (edit) Modernización, inmigración y mundo indígena. Temuco: Ediciones Universidad de La Frontera.

PINTO, Jorge (2001). La Formación del estado y Pueblo Mapuche. De la inclusión a la exclusión. Santiago: IDEA-USACH.

VILLALOBOS, Sergio (1995). Vida fronteriza en la Araucanía. Santiago: editorial Andrés Bello.

Recibido: 13 abril 2015 Aceptado: 29 mayo 2015 